\title{
Intercomparison of Sensible Heat Flux from Large Aperture Scintillometer and Eddy Covariance Methods: Field Experiment over a Homogeneous Semi-arid Region
}

\author{
Dawit A. Zeweldi • Mekonnen Gebremichael • \\ Junming Wang • Theodore Sammis · Jan Kleissl • \\ David Miller
}

Received: 10 April 2009 / Accepted: 1 December 2009 / Published online: 20 December 2009

(C) The Author(s) 2009. This article is published with open access at Springerlink.com

\begin{abstract}
Scintillometers are becoming increasingly popular for the validation of satellite remote sensing sensible heat-flux estimates due to the comparable spatial resolutions. However, it is important to gain confidence in the accuracy of the sensible heat-flux measurements obtained by the scintillometer. Large aperture scintillometer (LAS) and eddy-covariance (EC) measurements were collected over a homogeneous, dry and semi-arid region near Las Cruces, New Mexico, USA, where the homogeneity allowed direct comparison of the two instruments despite their differences in footprint sizes. The differences between the sensible heat-flux measured by both LAS and EC systems fall within the differences between two EC systems. We conclude that the large aperture scintillometer is a reliable system for measuring sensible heat flux in a dry semiarid region.
\end{abstract}

Keywords Eddy covariance $\cdot$ Large aperture scintillometer $\cdot$ Sensible heat flux · West Mesa desert

D. A. Zeweldi · M. Gebremichael ( $\varangle)$

Civil and Environmental Engineering Department, University of Connecticut,

261 Glenbrook Road, Unit 2037, Storrs, CT 06269-2037, USA

e-mail: mekonnen@engr.uconn.edu

J. Wang · T. Sammis

Department of Agronomy and Horticulture, New Mexico State University, Las Cruces,

NM 88003-8001, USA

J. Kleissl

Department of Mechanical and Aerospace Engineering, University of California-San Diego,

San Diego, CA 92093-0411, USA

D. Miller

Natural Resources management and Engineering Department, University of Connecticut, Storrs, CT 06269-4087, USA 


\section{Introduction}

Accurate estimates of sensible heat $(H)$ and latent heat $\left(L_{v} E\right)$ fluxes are critically important for water resource management, particularly in regions of water scarcity and a semi-arid climate. Remote sensing by satellite has long been identified as a technology capable of monitoring these surface fluxes. Surface fluxes cannot be measured directly from satellites, but can be estimated based on surface radiation fields through semi-empirical remote sensing algorithms. A typical approach identifies spectral bands particularly sensitive to surface heat fluxes, then empirical algorithms are developed to relate them to the radiances. The empirical approximation to the physical process may introduce errors in the remote sensing surfaceflux estimates, and so the quantification of these errors is essential to providing quantitative confidence to users, and feedback to algorithm developers so as to improve the accuracy of the algorithms.

Accurate estimation of the errors in satellite remote sensing surface-flux estimates requires a comparison against independent, high-quality, surface-flux data at the same horizontal resolution. It is generally agreed that the eddy-covariance (EC) technique is the most accurate means of measuring $H$, but such a measurement is only representative over a relatively small area (which changes with the wind direction) around the EC system. The scale discrepancy between eddy-covariance and satellite footprints introduces errors when evaluating satellite products based on EC data, particularly over heterogeneous areas. Using the scintillation technique scintillometers can provide path-averaged values of $H$ over distances of a few hundreds of metres up to $10 \mathrm{~km}$, and are therefore suitable for validation of remote sensing systems (Kleissl et al. 2009b). A disadvantage of this method is that, contrary to the EC technique, which uses direct turbulence measurements, scintillometry relies on the semiempirical Monin-Obukhov similarity theory for the calculation of $H$ (e.g., Hoedjes et al. 2007). Therefore it is important to assess the accuracy of $H$ estimates made by scintillometers before using them in the validation of satellite remote sensing algorithms. Several studies have examined the accuracy of $H$ estimates made by the large aperture scintillometer (LAS) over different land-surface conditions with significant moisture levels: flat pastoral surfaces (McAneny et al. 1995), a rangeland site (Hartogensis et al. 2003), a vineyard (de Bruin et al. 1995), agricultural fields in humid regions (de Bruin et al. 1995; Cain et al. 2001; Meijninger et al. 2002; Beyrich et al. 2002; Kleissl et al. 2009a), and complex terrain (Chehbouni et al. 2000). All these studies reported that LAS gives reliable $H$ estimates.

In this study, we report on the results of a two-day (May 28-29, 2008) field experiment in which we deployed one LAS and two EC systems over a homogeneous, sparsely vegetated, semi-arid region of New Mexico, USA in order to evaluate the accuracy of LAS $H$ estimates. The two EC systems quantify the relative difference in the performance between the EC systems, and hence the limitation of the EC system in evaluating the LAS system. This homogeneous land surface allows evaluating the accuracy of LAS $H$ estimates using EC sensors without introducing substantial errors, since the discrepancy in the footprint size between LAS and EC is not an issue.

\section{Field Experiment}

The field site is located in the West Mesa desert around Las Cruces, New Mexico, USA at latitude $32^{\circ} 17^{\prime} \mathrm{N}$, longitude $106^{\circ} 55^{\prime} \mathrm{W}$, and an elevation of $1,285 \mathrm{~m}$ above mean sea level. It has a homogenous land cover of sparsely vegetated short shrubs locally known as 
"Mesquite" and "Creso" with an average height of about $0.8 \mathrm{~m}$. Figure 1a shows the overall plan layout of the experiment.

\subsection{Large Aperture Scintillometer Data Processing}

Figure 1a shows the deployed LAS system. The LAS model used was the BLS900 (aperture diameter of $0.145 \mathrm{~m}$ ) manufactured by Scintec and consisting of a double beam transmitter and a receiver. We mounted the transmitter and receiver on a tower so that the beam along the path length had an effective path height of $2.5 \mathrm{~m}$ above the surface based on the method given in the Scintec manual. The separation distance (path length $\mathrm{L}$ ) between the transmitter and receiver was $800 \mathrm{~m}$. The LAS output was recorded and stored internally as 2-min averages using a $25 \mathrm{~Hz}$ transmitter setting.

The LAS transmitter emits electromagnetic radiation at $880 \mathrm{~nm}$, which is scattered by the turbulent atmosphere and part of which reaches the receiver. As shown by Wang et al. (1978), the intensity fluctuations measured at the receiver are related to the path-averaged



Fig. 1 a Layout of the deployed large aperture scintillometer and two eddy-covariance systems in the experimental site near Las Cruces, New Mexico, U.S.A. (Source of background photo is Google Earth), b location of localized dense vegetation with respect to EC2, and c location of localized dense vegetation with respect to $\mathrm{EC} 1$ 
structure parameter of the refractive index of air $\left(C_{n}^{2}\right)$. For scintillometers operating at visible and near-infrared wavelengths, $C_{n}^{2}$ is related to the structure parameter of temperature $C_{T}^{2}$ (Wesely 1976; Moene 2003):

$$
C_{n}^{2}=\left(-0.78 \times 10^{-6} P / T^{2}\right)^{2} C_{T}^{2}(1+0.03 / \beta)^{2},
$$

where $P$ is atmospheric pressure and $\beta$ is the Bowen ratio, and where the humidity correction term is neglected for dry surface conditions. We used the Monin-Obukhov similarity theory (Wyngaard et al. 1971) to calculate $H$ iteratively from $C_{T}^{2}$ and additional wind speed data through the following relationship:

$$
\begin{gathered}
\frac{C_{T}^{2}\left(Z_{L A S}-d\right)^{\frac{2}{3}}}{T_{*}^{2}}=f_{T}\left(\frac{Z_{L A S}-d}{L_{M O}}\right)=c_{T_{1}}\left(1-c_{T_{2}} \frac{Z_{L A S}-d}{L_{M O}}\right)^{-\frac{2}{3}}, \\
L_{M O}=-\left(\rho c_{p} T u_{*}^{3} / k g H\right), \\
T_{*}=\left(-H / \rho c_{p} u_{*}\right), \\
u_{*}=k u\left[\ln \left(\frac{z_{m}-d}{z_{0 m}}\right)-\psi_{m}\left(\frac{z_{m}-d}{L_{M O}}\right)+\psi_{m}\left(\frac{z_{0 m}}{L_{M O}}\right)\right]^{-1},
\end{gathered}
$$

where $z_{m}(=1.85 \mathrm{~m})$ is the height above the surface at which wind speed, $u$, is measured, $z_{L A S}(=2.50 \mathrm{~m})$ is the effective height of the LAS above the surface, $z_{0 m}(=0.08 \mathrm{~m})$ is the aerodynamic roughness length taken as $10 \%$ of the vegetation height, $\psi_{m}$ is the momentum stability correction function, and the displacement height $d$ for sparsely vegetated short shrubs of West Mesa desert is assumed zero following Stull (1988), $u_{*}$ is the friction velocity, $\rho$ is the density of air, $k$ is the von Karman constant, and $g$ is the gravitational acceleration. The empirical constants $C_{T_{1}}$ and $C_{T_{2}}$ are taken as 4.9 and 6.1 respectively for the correction function $f_{T}$ for unstable conditions (Andreas 1989; de Bruin et al. 1993). For a detailed discussion of scintillometer theory and data processing, see Hill (1992); de Bruin (2002); Hoedjes et al. (2007), and Kleissl et al. (2008).

\subsection{Eddy-Covariance Data Processing}

As shown in Fig. 1a, we also installed two EC systems: one EC close to the transmitter, and the other EC close to the receiver. The EC systems were manufactured by Campbell Scientific, and consist of CSAT3 Sonic Anemometer and FW05 fine-wire thermocouples. Each EC system, hereinafter called EC1 and EC2, is set up at a height of $2 \mathrm{~m}$ above the ground surface and with an average height of about $1.2 \mathrm{~m}$ above the top of the nearby vegetation. In this study the EC sensors measure fluctuations of vertical wind speed and air temperature at a sampling frequency of $20 \mathrm{~Hz}$ and the heat fluxes are computed at a block averaging period of $30 \mathrm{~min}$.

$H$ from the EC system is computed as the covariance between fluctuations of vertical wind speed and fluctuations of temperature (e.g., Stull 1988; Moncrieff et al. 1997; Van Dijk et al. 2004):

$$
H=\rho C_{p} \overline{w^{\prime} T^{\prime}}
$$

where $\rho$ is air density $C_{p}$ is the specific heat capacity of air, $\overline{w^{\prime} T^{\prime}}$ is the covariance between vertical wind speed $(w)$ and air temperature $(T)$, and the overbar indicates time averaging. However, before computing $H$ from the covariance of $w$ and $T$, we applied typical corrections for alignment of wind vectors with the mean flow and poor frequency response. 
We aligned the pre-processed wind vectors to the mean stream flow by rotating them following the natural-wind-coordinate rotation method given by Wilczak et al. (2001). We used the aligned wind vectors for further analysis. The EC method is known to suffer from poor frequency response (e.g., McMillen 1988; Kaimal et al. 1989; Laubach and McNaughton 1999), so we followed the analytical approximation method given by Massman (2000) to correct for the effect of poor frequency response.

\subsection{Fooprint for EC Systems}

A major challenge in using EC to validate LAS is the discrepancy in the footprint between the two systems. Since the LAS is most sensitive in the centre of the beam, the LAS footprint usually takes the shape of an ellipsoid with a length of about $2 / 3$ of the transect length (Kleissl et al. 2009b). In the convective conditions encountered at the site, the ellipsoid is located a short distance upwind of the transect. The effect of the discrepancy on the $H$ comparison depends on the degree of variability of $H$ : the effect is smaller for a spatially less variable $H$ (i.e. for homogeneous land-surface conditions) and the effect is greater for a spatially more variable $H$. Although our study region is close to being homogeneous, there are localized dense vegetation areas close to the EC systems (see the dark patches in Fig. 1). Are these patches significant enough to dominate the EC footprints, making the EC systems unsuitable for the validation of LAS H estimates? To investigate this issue, we performed a footprint analysis of the EC systems.

As shown in Fig. 1b and c, the dark patches are located more than $80 \mathrm{~m}$ from EC2 and more than $275 \mathrm{~m}$ from EC1. Using wind speed of $4 \mathrm{~m} \mathrm{~s}^{-1}$ (which is the average wind speed in the area at the time of measurement), out of the total footprint of EC1, 50\% would be contributed by areas within 40 to $50 \mathrm{~m}$ radii from EC1 and $90 \%$ would be contributed by areas within 250 to $260 \mathrm{~m}$ radii from EC1. This indicates that the dark patches (which are located more than $275 \mathrm{~m}$ away from the EC system and along a specific direction) do not make a significant contribution to the footprint of EC1.

For EC2, the dark patches only affect the footprint if the wind direction is from the southsouth-east. Figure 2 shows the relative frequency of the wind direction at EC2, for each of the experiment dates. This Figure shows that the frequency of wind direction from the south-south-east is $9.8 \%$ on May 28 and $3.7 \%$ on May 29, indicating that the dark patches do not dominate the footprint of EC2.

In addition, the total precipitation measured in the area, from January 1, 2008 until the end of the experiment, was only $5 \mathrm{~mm}$ and this was due to a one-day rain event on March 9, 2008. Therefore, the latent heat flux from the patches of vegetation can be assumed to be small.

The above analysis confirms that the region covered by the LAS and EC systems is fairly homogeneous, and hence our working assumption of using EC systems to evaluate the accuracy of LAS $H$ estimates is realistic.

\section{Results and Discussion}

Figure 3 shows the diurnal course of 30-min averaged $H$ obtained from the LAS (i.e. $H_{L A S}$ ), from the first EC system (i.e. $H_{E C 1}$ ), and from the second EC system (i.e. $H_{E C 2}$ ). All measurements showed a similar strong diurnal cycle in $H$. During stable and weak unstable conditions, there was good agreement among $H_{L A S}, H_{E C 1}$, and $H_{E C 2}$. However, during unstable conditions, there were some differences between $H_{L A S}$ and $H_{E C 1}$, and even between 

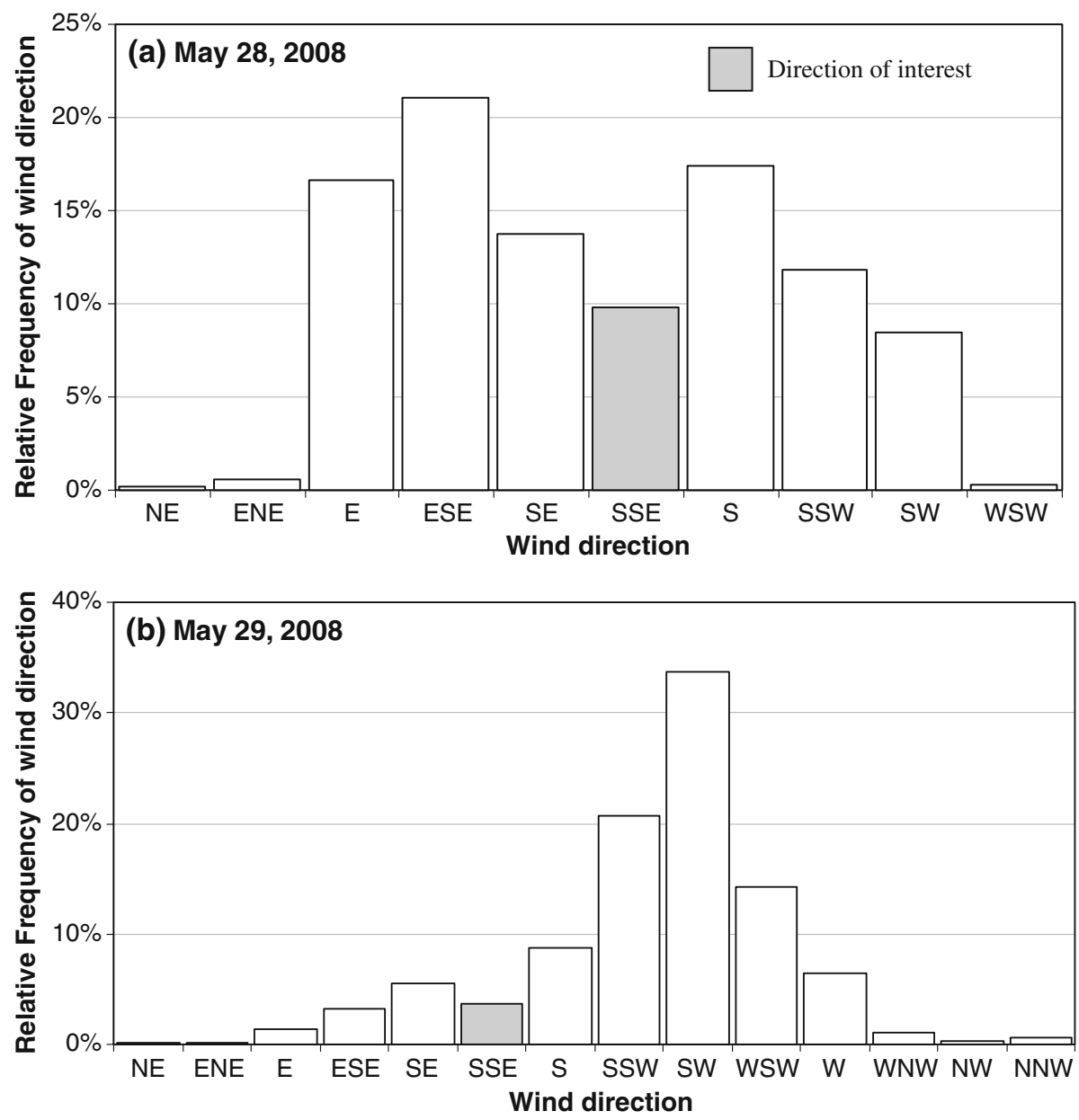

Fig. 2 Relative frequency of wind direction at the EC1 location for (a) May 28, and (b) May 29, 2008

$H_{E C 1}$ and $H_{E C 2}$. Overall, $H_{L A S}$ tended to be slightly higher than $H_{E C 1}$ and $H_{E C 2}$ during unstable conditions.

To statistically measure the agreement of the three instruments, we used the following three dimensionless statistics: (1) linear correlation coefficient $r$, (2) bias ratio defined as $\bar{H}_{L A S} / \bar{H}_{E C}$, and (3) root-mean-square error normalized by the mean $H_{E C}$ (nrmse). Figure 4 shows the scatterplots of $H_{L A S}$ vs. $H_{E C 1}$, and $H_{L A S}$ vs. $H_{E C 2}$, using data from both measurement days, also shown in the plots are the three performance statistics. The linear correlation coefficient between $H_{L A S}$ and $H_{E C}$ was 0.89 for EC1, and 0.79 for EC2. We found a correlation of 0.87 between $H_{E C 1}$ and $H_{E C 2}$, indicating that the agreement between LAS and EC was similar to the agreement between two EC systems. The bias was slightly positive showing that the LAS overestimated $H$ by $6 \%$ compared to EC 1 and by $2 \%$ compared to the EC2. EC1 underestimates $H$ by $4 \%$ compared to EC2, indicating that the bias in $H$ found for the LAS is very close to the relative bias between EC1 and EC2. The overall difference, including both systematic and random errors, between $H_{L A S}$ and $H_{E C}$, as measured by the 


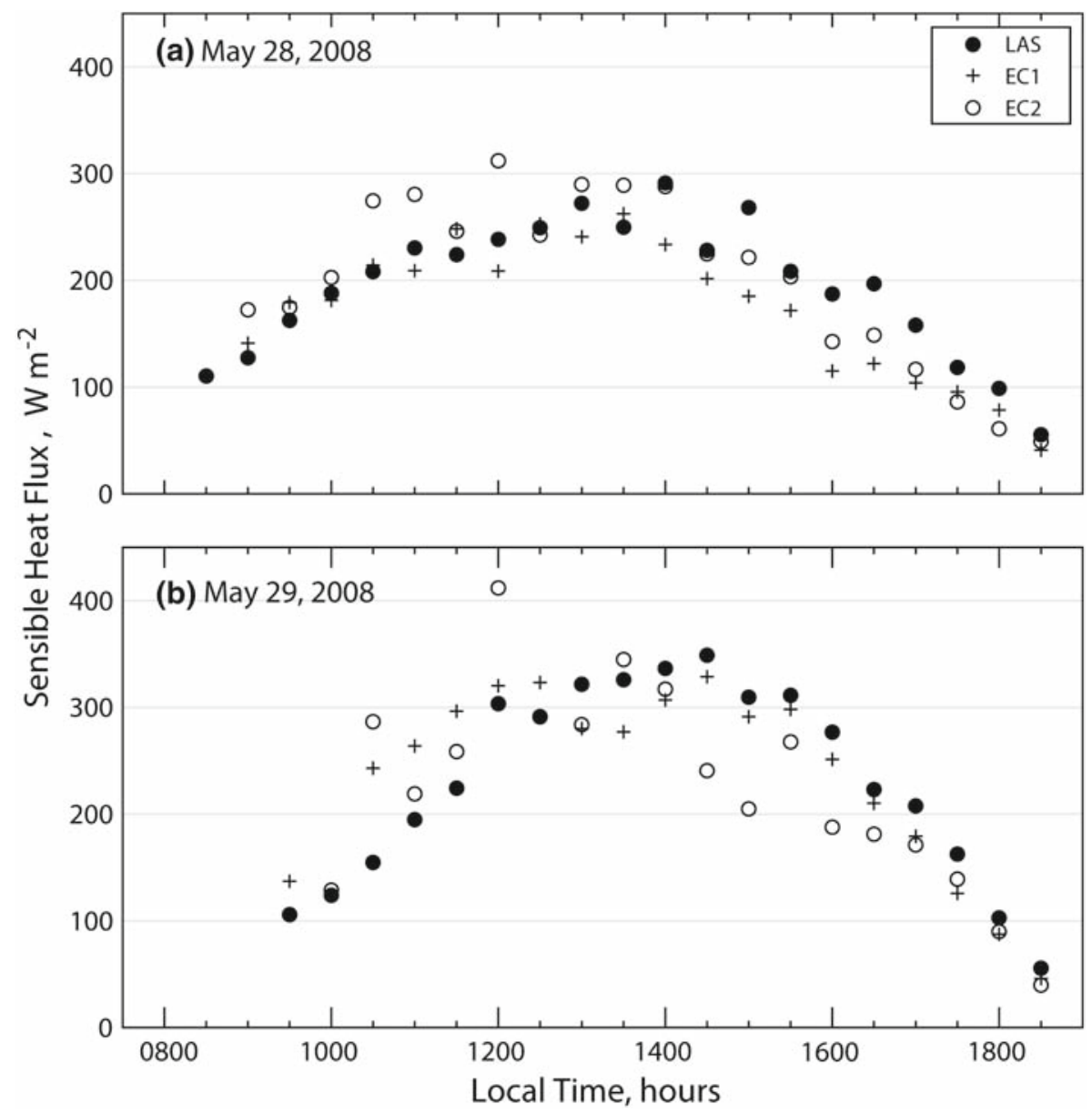

Fig. 3 Diurnal course of 30-min averaged sensible heat flux derived from LAS, EC1, and EC2, for a May 28, and b May 29, 2008

nrmse, varies between $19 \%$ and $24 \%$, which is close to the $21 \%$ we found between $H_{E C 1}$ and $H_{E C 2}$. Therefore, the statistics reveal that, (1) the $H$ values obtained by LAS are very close to those obtained by EC, and (2) the difference in $H$ between LAS and EC is very close to the difference between the EC systems.

\section{Conclusions}

We have evaluated the performance of LAS in estimating $H$ over a homogenous semi-arid region in New Mexico, USA, by comparison with independent measurements from two EC systems. The homogeneous land surface presented an opportunity for a realistic direct comparison between $H_{L A S}$ and $H_{E C}$ that represent different footprint sizes and areas. Our results reveal that the $H$ values obtained by large aperture scintillometry are very close to those obtained by eddy covariance, and the differences in $H$ between LAS and EC are very close 



Fig. 4 Comparison of 30-min averages, derived from a $H_{L A S}$ and $H_{E C 1}$, and $\mathbf{b} H_{L A S}$ and $H_{E C 2}$

to those between the EC systems. Therefore, we conclude that large aperture scintillometry is a reliable system for measurement of sensible heat flux in a dry semiarid region.

Acknowledgements This research was supported NASA NIP Grant NNX08AR31G. The field experiment was partially supported by the University of Connecticut's Center for Environmental Sciences and Engineering.

Open Access This article is distributed under the terms of the Creative Commons Attribution Noncommercial License which permits any noncommercial use, distribution, and reproduction in any medium, provided the original author(s) and source are credited.

\section{References}

Andreas EL (1989) Estimating $C_{n}^{2}$ over snow and sea ice from meteorological data. J Opt Soc Am 5: 481-495

Beyrich F, de Bruin HAR, Meijininger WML, Schipper JW, Lohse H (2002) Results from one-year continuous operation of a large aperture scintillometer over heterogeneous land surface. Boundary-Layer Meteorol 105:85-97

Cain JD, Rosier PTW, Meijninger W, de Bruin HAR (2001) Spatially averaged sensible heat fluxes measured over Barley. Agric Forest Meteorol 107:307-322

Chehbouni A, Watts C, Lagouarde JP, Kerr YH, Rodriguez JC, Santiago JMF, Dedieu G, Goodrich DC, Unkrich C (2000) Estimation of heat fluxes and momentum fluxes over complex terrain using a large aperture scintillometer. Agric Forest Meteorol 105:215-226

de Bruin H (2002) Introduction: renaissance of scintillometry. Boundary-Layer Meteorol 105(1):1-4

de Bruin HAR, Kohsiek W, Van den Hurk BJJM (1993) A verification of some methods to determine the fluxes of momentum, sensible heat and water vapour using standard deviation and structure parameter of scalar meteorological quantities. Boundary-Layer Meteorol 63:231-257

de Bruin HAR, Van den Hurk BJJM, Kohsiek W (1995) The scintillation method tested over a dry vineyard area. Boundary-Layer Meteorol 76:25-40

Hill RJ (1992) Review of optical scintillation methods of measuring the refractive index spectrum, inner scale and surface fluxes. Waves Random Media 2:179-201

Hartogensis OK, Watts CJ, Rodriguez J-C, de Bruin HAR (2003) Derivation of an effective height for scintillometers: La Poza experiment in Northwest Mexico. J Hydromet 4:915-928

Hoedjes JCB, Chehbouni A, Ezzahar J, Escadafal R, de Bruin HAR (2007) Comparison of large aperture scintillometer and eddy covariance measurements: can thermal infrared data be used to capture footprint-induced difference? J Hydromet 8:144-159

Kaimal JC, Clifford SF, Lataitis RJ (1989) Effect of finite sampling on atmospheric spectra. BoundaryLayer Meteorol 47:337-347 
Kleissl J, Gomez J, Hong S-H, Hendrickx JMH, Rahn T, Defoor WL (2008) Large aperture scintillometer intercomparison study. Boundary-Layer Meteorol 128:133-150

Kleiss1 J, Watts CJ, Rodriguez JC, Naif S, Vivoni ER (2009) Scintillometer intercomparison study—continued. Boundary-Layer Meteorol 130(3):437-443

Kleissl J, Hong S-H, Hendrickx JMH (2009) New Mexico scintillometer network: supporting remote sensing and hydrologic and meteorological models. Bull Am Meteorol Soc 90(2):207-218

Laubach J, McNaughton KG (1999) A Spectrum-independent procedure for correcting eddy fluxes measured with separated sensors. Boundary-Layer Meteorol 89:445-467

Massman W (2000) A simple method for estimating frequency response corrections for eddy covariance systems. Agric Forest Meteorol 104:185-198

McAneny KJ, Green AE, Astill MS (1995) Large aperture scintillometery: the homogeneous Case. Agric Forest Meteorol 76:149-162

McMillen RT (1988) An eddy correlation technique with extended applicability to non-simple terrain. Boundary-Layer Meteorol 43:231-245

Meijninger W, Hartogensis O, Kohsiek W, Hoedjes J, Zuurbier R, de Bruin HAR (2002) Determination of area averaged sensible heat fluxes with a large aperture scintillometer over a heterogeneous surface: Flevoland field experiment. Boundary-Layer Meteorol 105:63-83

Moene AF (2003) Effects of water vapour on the structure parameter of the refractive index for near-infrared radiation. Boundary-Layer Meteorol 107:635-653

Moncrieff JB, Massheder JM, de Bruin HAR, Elbers J, Friborg T, Heusinkveld B, Kabat P, Scott S, Soegaard H, Verhoef A (1997) A system to measure surface fluxes of momentum, sensible heat, water vapour and carbon dioxide. J Hydrol 188(189):589-611

Stull RB (1988) An introduction to boundary layer meteorology. Kluwer Academic Publishers, Dordrecht, $666 \mathrm{pp}$

Van Dijk A, Moene AF, de Bruin HAR (2004) The principles of surface flux physics: theory, practice and description of the ECPACK library. Internal Report 2004/1, Meteorology and Air Quality Group, Wageningen University, Wageningen, The Netherlands, 99 pp

Wang TI, Ochs GR, Clifford SF (1978) A saturation resistant optical scintillometer to measure $C_{n}^{2}$. J Opt Sco Am 69:334-338

Wesely ML (1976) The combined effect of temperature and humidity on the refractive index. J Appl Meteorol 15:43-49

Wilczak JM, Oncley SP, Sage SA (2001) Sonic anemometer tilt correction algorithms. Boundary-Layer Meteorol 99:127-150

Wyngaard JC, Izumi Y, Collins SA Jr (1971) Behavior of the refractive index structure parameter near the ground. J Opt Sco Amer 61:1646-1650 